\title{
Contribution to the Artifical Neural Network Speed Estimator in a Degraded Mode for Sensor-Less Fuzzy Direct Control of Torque Application Using Dual Stars Induction Machine
}

\author{
Hechelef Mohammed, Abdelkader Meroufel \\ Faculty of Engineering Sciences, Electrical Engineering Department \\ Djillali Liabes University Sidi Bel Abbes Algeria
}

\begin{tabular}{l} 
Article Info \\
\hline Article history: \\
Received Jan 19, 2015 \\
Revised Apr 4, 2015 \\
Accepted Apr 28, 2015 \\
\hline
\end{tabular}

Keyword:

ANN

de Sensor-Less

Degraded Mode

DSIM

DTC

\begin{abstract}
Recently one of the major topic of research is the involvement of the intelligence artificial in the control system. This paper deals with application of a new combination between two-control strategy known as fuzzy direct control of torque and then an adaptive Neuronal Speed estimator utilizing dual starts induction motor. The research discussed consist to replace the switching table used in the conventional direct control method and adaptive mechanism of the classic MRAS estimator with fuzzy controller and new neural network accordingly, both strategies can manage the degraded and normal modes. The neural networks used are the back-propagation, to reduce the training patterns and increase the execution speed of the training process. As results we achieved can be summarised as follows: 1) high degree of reliability of speed estimation even with using only one start voltages and currents and parameters; 2) Minimization of the torque and flux ripples; and 3) Minimization of the current total harmonic distortion.
\end{abstract}

Copyright (C) 2015 Institute of Advanced Engineering and Science. All rights reserved.

\section{Corresponding Author:}

Abdelkader Meroufel,

Faculty of Engineering Sciences. Electrical Engineering Department,

Djillali Liabes University Sidi Bel Abbes Algeria.

Email: hmed14@yahoo.fr

\section{INTRODUCTION}

Most recently, the introduction of an artificial neural network has started to play an increasing role in modeling and control of speed estimators. For example, when used within a specific railway application; "Feedback of the wheel speeds in high-speed traction system". When the speed sensor is defective occupies a large area on the nowadays speed sensor-less application researchs, which raises the following question how can the speed be estimated in a degraded mode?

The design of ANN estimator's solution is based on the training of the recurrent and feed forward neural network, which manages and controls both the normal and degraded modes.

The dual start induction machine will provide the end user more options to estimate the speed by using the two-start windings outputs as the currents and voltages in normal mode, or alternatively only one start outputs when the output of the second starts are not available in a degraded mode.

Additionally when there is a need to increase system performance, particularly when facing limits on the power ratings of power supplies and semiconductors level constraints, the dual start induction machine shall motivate the use of phase number other than three, new machine design criteria and the use of harmonic current and flux components. In a multi-phase system, it shall be assumed a system that comprises more than the conventional three phases; the machine output power can be divided into two or more solid-state inverters.

Accepting the above commentary and conclusion takes one to the next level to study in this paper the ANN speed estimator when only one start data's are available. 
Within the paper, a small power dual start induction machine was used to study the combination of two types of artificial intelligence when a series of tests shows that the high quality of the speed estimation and the effectiveness of the targeted and proposed solution.

The paper is organized as follows;

Start with model of a DSIM which has been developed, then a direct torque control (DTC) theory algorithm will be introduced Next a fuzzy logic technique shall be used in the DTC in Section 2. After that, proposed neural rotor speed estimation use the voltage and current of the first start. This will be included with Section 3, in the end of the same section we presented a Simulink Fuzzy DTC model. Within Section 5, a selection of the simulation results will be integrated as sample review documentation. The closing section shall encompass a set of remarks and a conclusion statement.

This paper is organized as follows. First, DTC theory algorithm is introduced in Section 2. Then, the fuzzy logic technique used in DTC, after that, a proposed neural rotor speed estimation use the voltage and current of the first start, is presented in Section 3. In the Section 4, some simulation results are presented. Finally, some concluding remarks are stated in the last Section.

\section{MODELING OF THE DOUBLE STAR INDUCTION MOTOR}

The dual star asynchronous machine. Whose Figure 1 expresses the windings of the double star induction machine and the offset angle between the two stars windings [1].

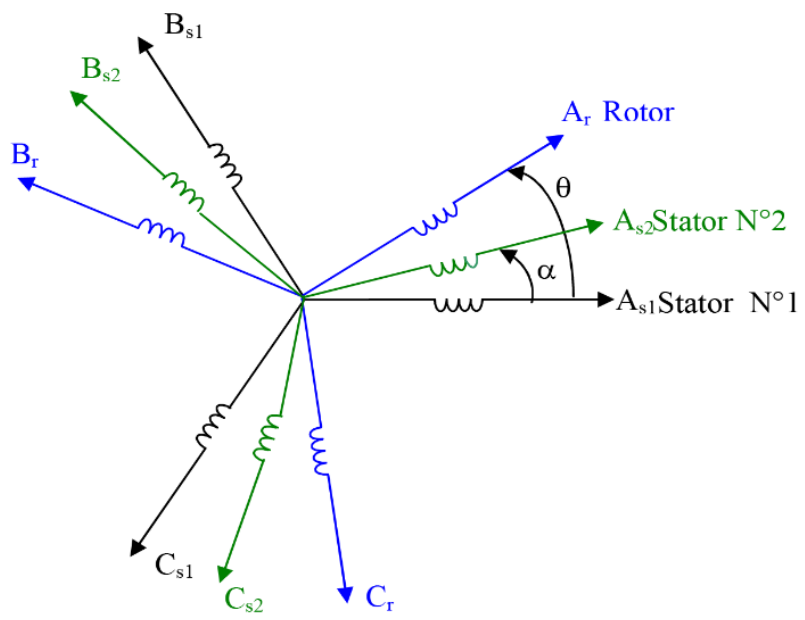

Figure 1. Shows the winding and offset angles

$-\mathrm{A} 1, \mathrm{~B} 1, \mathrm{C} 1$ : Winding of stator 01 .

$-\mathrm{A} 2, \mathrm{~B} 2, \mathrm{C} 2$ : Winding of stator 02

$-\alpha$ : offset angle between two stators.

$-\theta$ : offset angle between the rotative part and the stators $01 \& 02$.

The mathematical model of the machine is can be expressed by the following set of electrical/mechanical equations

The first star:

$$
\left[\text { Vabc, } s_{1}\right]=\left[\mathrm{Rs}_{1}\right]\left[\mathrm{abc}, \mathrm{s}_{1}\right]+\frac{\mathrm{d}\left[\varphi \mathrm{abc}, \mathrm{s}_{1}\right]}{\mathrm{dt}}
$$

The second start:

$$
\left[\text { Vabc, } s_{2}\right]=\left[\mathrm{Rs}_{2}\right]\left[\mathrm{abc}, \mathrm{s}_{2}\right]+\frac{\mathrm{d}\left[\varphi \mathrm{abc}, \mathrm{s}_{2}\right]}{\mathrm{dt}}
$$

For the rotative part: 


$$
[\mathrm{Vabc}, \mathrm{r}]=[\mathrm{Rr}][\mathrm{abc}, \mathrm{r}]+\frac{\mathrm{d}[\varphi \mathrm{abc}, \mathrm{r}]}{\mathrm{dt}}
$$

The mechanical equations:

$$
\mathrm{J} \frac{\mathrm{d} \Omega}{\mathrm{dt}}=\mathrm{Tem}-\mathrm{Tr}-\mathrm{kf} \Omega
$$

Where $\mathrm{J}$ is the moment inertia of the rotating parts, $\mathrm{K}_{\mathrm{f}}$ is the friction coefficient related to the engine bearings, and $\mathrm{T}_{\mathrm{em}}$ represents the torque loading [2].

The electrical state variables in " $\alpha \beta$ " system are the electrical flux, and the input variable in the system " $\alpha \beta$ " expressed by the vector [U] then the state space representation of the machine can be modeled and expressed in the form:

$$
\dot{\mathrm{X}}=\frac{\mathrm{dX}}{\mathrm{dt}}=\mathrm{AX}+\mathrm{BU}
$$

With X: state variables

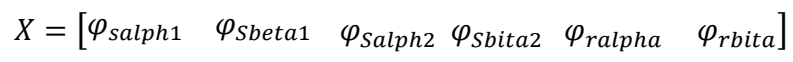

A: system evolution matrix

$$
\mathrm{A}=\left[\begin{array}{llllll}
\text { A11 } & \text { A12 } & \text { A13 } & \text { A14 } & \text { A15 } & \text { A16 } \\
\text { A21 } & \text { A22 } & \text { A23 } & \text { A24 } & \text { A25 } & \text { A26 } \\
\text { A31 } & \text { A32 } & \text { A33 } & \text { A34 } & \text { A35 } & \text { A36 } \\
\text { A41 } & \text { A42 } & \text { A43 } & \text { A44 } & \text { A45 } & \text { A46 } \\
\text { A51 } & \text { A52 } & \text { A53 } & \text { A54 } & \text { A55 } & \text { A56 } \\
\text { A61 } & \text { A62 } & \text { A63 } & \text { A64 } & \text { A65 } & \text { A66 }
\end{array}\right]
$$

B: control Vector

$$
\mathrm{B}=\left[\begin{array}{llllll}
1 & 0 & 0 & 0 & 0 & 0 \\
0 & 1 & 0 & 0 & 0 & 0 \\
0 & 0 & 1 & 0 & 0 & 0 \\
0 & 0 & 0 & 1 & 0 & 0 \\
0 & 0 & 0 & 0 & 0 & 0 \\
0 & 0 & 0 & 0 & 0 & 0
\end{array}\right]
$$

$\mathrm{U}$ : input vector it is represented by the tension vector

$$
\mathrm{U}=\left[\begin{array}{llll}
\mathrm{V}_{\text {Salph1 }} & \mathrm{V}_{\text {Sbeta1 }} & \mathrm{V}_{\text {Salph2 }} & \mathrm{V}_{\text {Sabeta2 }}
\end{array}\right]
$$

\section{PRINCIPLE OF DIRECTE CONTROL OF TORQUE}

Direct control of torque, is an approach that allows control of the direct switch converter using a simple algorithm. The DTC (Direct Torque control) appeared in the 1980, after a variety of algorithms has been proposed based on refinements developed from heuristic switching choices [3],

If we consider the first start and the equations which are used for vectorial representation of the stator characteristics of the machine, binds to the stator reference.

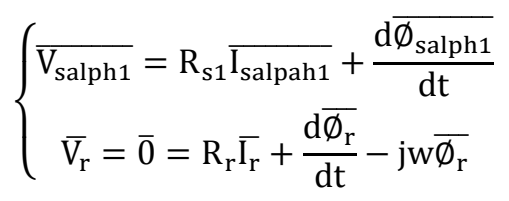

From the electrical flux expression, the rotor current can be expressed as: 


$$
\overline{\mathrm{I}_{\mathrm{r}}}=\frac{1}{\sigma}\left(\frac{\overline{\emptyset_{\mathrm{r}}}}{\mathrm{L}_{\mathrm{r}}}-\frac{\mathrm{L}_{\mathrm{m}}}{\mathrm{L}_{\mathrm{r}} \mathrm{L}_{\mathrm{s}}} \overline{\emptyset_{\text {salph } 1}}\right)
$$

With the dispersion coefficient

$$
\sigma=1-\frac{L_{m}^{2}}{L_{s} L_{r}}
$$

The expressions (10) become

$$
\left\{\begin{array}{l}
\overline{V_{\text {salph } 1}}=R_{\text {s1 }} \overline{I_{\text {salpah } 1}}+\frac{d \overline{\emptyset_{\text {salph} 1}}}{d t} \\
\frac{d \overline{\emptyset_{\mathrm{r}}}}{d t}+\left(\frac{1}{\sigma \tau_{\tau}}-j w\right) \overline{\emptyset_{r}}=\frac{L_{m}}{L_{s}} \frac{1}{\sigma \tau_{\tau}} \overline{\emptyset_{\text {salph } 1}}
\end{array}\right.
$$

Relation (11) shows that:

*It is possible to control the flux vector $\emptyset_{\text {salph } 1}$ by acting on the voltage vector $\overrightarrow{V S}$ as we can consider the the voltage drop $\mid$ RsIs $\mid$ so small if comparing with voltage vector value $|\overrightarrow{V S}|$ in the period $\left[0 \mathrm{~T}_{\mathrm{e}}\right.$ ]

*The rotor act as a filter with (time constant $\sigma \tau_{\tau}$ ) between the flux $\emptyset_{\text {salph } 1}$ and $\emptyset_{r}$. Moreover, $\emptyset_{r}$ reach his steady state value as follow:

$$
\overline{\emptyset_{\mathrm{r}}}=\frac{\mathrm{L}_{\mathrm{m}}}{\mathrm{L}_{\mathrm{s}}} \frac{\overline{\emptyset_{\text {salph } 1}}}{1+\mathrm{jwr} \sigma \tau}
$$

By putting: $\gamma=\left(\overline{\emptyset_{s}} \overline{\emptyset_{r}}\right)$ : The representation of torque expression becomes:

$$
\Gamma_{\text {elm }}=p \frac{\mathrm{L}_{\mathrm{m}}}{\sigma \mathrm{L}_{\mathrm{r}} \mathrm{L}_{\mathrm{s}}} \phi_{\text {salpha } 1} * \phi_{\mathrm{r}} \sin (\gamma)
$$

The expression (13) shows that:

*The torques value is dependents of the amplitude of two vectors $\overrightarrow{\phi_{\text {salpha1 }}}$ and $\overrightarrow{\phi_{\mathrm{r}}}$ with relative position.

* If we manage well the control of the flux vector $\overrightarrow{\phi_{\text {salpha1 }}}$ by acting on the module and the voltage vector position, therefore it is possible to control the amplitude and the relative position of $\overrightarrow{\phi_{\mathrm{r}}}$,

*This is possible only if the control period Te of the voltage $\overrightarrow{V S}$ satisfies this condition. $T_{e} \ll \sigma \tau_{\tau}$

\subsection{Setting of the Stator flux}

The expression of the stator flux with the reference associated to the stator is obtained from the following equation

$$
\emptyset_{s j}=\int_{0}^{t}(V s j+\text { RsjIsj)dt } \quad j=1,2
$$

Using interval $[0, \mathrm{Te}]$ corresponding to a sampling period $(\mathrm{Te})$, the switch state $(\mathrm{Sa} \mathrm{Sb} \mathrm{Sc})$ are fixed, and if we consider the value, $\left|R s I_{s}\right|$ to be negligible when compared with voltage $\overrightarrow{|V s|}$ weicaniassume:

$$
\emptyset \mathrm{sj}(\mathrm{t}) \approx \emptyset_{\mathrm{S} 0}+\mathrm{V}_{\mathrm{Sj}} \mathrm{T}_{\mathrm{E}}
$$

With $\varphi_{\text {so }}$ being the flux vector at Time $\mathrm{t}=0$

This relation shows that if we apply a non-zero voltage vector, the end of the stator flux vector moves on a straight line whose direction the applied voltage gives vector. Figure 2 illustrates this principle, taking as example the voltage vector (V3). 


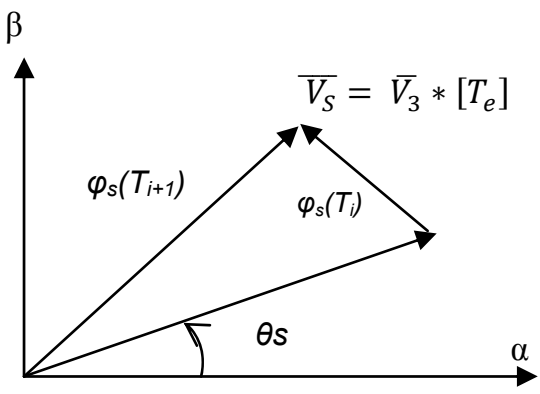

Figure 2. Evolution of the end of the flux i.e $\left(\overline{V_{S}}=\overline{V_{3}}\right)$

\subsection{Control of the Electromagnetic Torque}

In a steady state, we can assume for simplicity that the stator flux vector $\overrightarrow{\emptyset_{s}}$ rotates with a constant amplitude $\left|\emptyset_{s 0}\right|$, and with an average speed $W_{s 0 \mathrm{~s}}$. It can also be assumed that the rotor flux vector maintains constant amplitude and rotates with same pulsation $\omega_{\mathrm{s} 0}$ as the vector $\overrightarrow{\emptyset_{s}}$. We put at $t_{0}$;

$$
\left\{\begin{array}{l}
\overline{\emptyset_{s}}=\emptyset_{\mathrm{so}} \mathrm{e}^{\mathrm{j} \theta_{\mathrm{so}}} \\
\overline{\emptyset_{\mathrm{r}}}=\emptyset_{\mathrm{ro}} \mathrm{e}^{\mathrm{j} \theta_{\mathrm{ro}}}
\end{array}\right.
$$

Based on the flux, current and electromagnitc torque mentioned above, the electromagnetic torque equation could be transformed to a sinusoidal form as follows:

$$
\Gamma_{\text {elm }}=\mathrm{P} \frac{\mathrm{L}_{\mathrm{m}}}{\sigma \mathrm{L}_{\mathrm{s}} \mathrm{L}_{\mathrm{r}}} \emptyset_{\text {so }} \emptyset_{\text {ro }} \sin \left(\gamma_{0}\right)
$$

where $\gamma_{0}$ is the angle between the stator and the flux rotor vector.

If we Apply at $t_{0}$ an adequate voltage vector $\vec{V}_{s}$, and we impose along with a pulse $\Delta W_{s 1}$ as rotational speed and Immediately after $t_{0}$, we can note that there is a changes on stator and rotor flux:

$$
\left\{\begin{array}{l}
\emptyset_{s}=\emptyset_{s o} e^{j\left(\theta_{s o}+\Delta \theta_{s}\right)} \\
\emptyset_{r}=\left(\emptyset_{s o}+\Delta \emptyset_{r}\right) e^{j\left(\theta_{r o}+\Delta \theta_{r}\right)}
\end{array}\right.
$$

with:

$$
\Delta \theta_{s}=\left(w_{s o}+\Delta w_{s 1}\right)\left(t-t_{o}\right)
$$

From the flux rotor (18) expression, we can deduce the value derivative of this quantity:

$$
\frac{d \emptyset_{r}}{d t}=\frac{d \Delta \emptyset_{r}}{d t} e^{j \theta_{r}}+j \frac{d \Delta \theta_{r}}{d t} \emptyset_{r 0}
$$

with:

$$
\Delta \theta_{r}=\Delta \theta_{s}-\Delta \gamma
$$

With the same way, we can prove that: the Rotor flux vector keep turning with the same pulsation $\Delta W_{s 0}$ and maintaining the same amplitude $\overline{\Phi_{r 0}}[3]$. So after $t_{0}$ the torque equation can be expressed as:

$$
\Gamma_{\text {elm }}=\mathrm{P} \frac{\mathrm{L}_{\mathrm{m}}}{\sigma \mathrm{L}_{\mathrm{s}} \mathrm{L}_{\mathrm{r}}} \emptyset_{\text {so }} \emptyset_{\mathrm{so}} \sin \left(\gamma_{0}+\Delta \gamma\right)
$$

\subsection{Selection of the Voltage Vector}

The position of the flux vector can be determined from its components $\emptyset_{\text {salph }}$ and $\emptyset_{\text {sbeta }}$ When the flux vector is located inside sector $i$, the two vectors $V_{i}$ et $V_{i+3}$ have the bigger flux component . In addition, their effect on the torque depends of the position of the flux vector in the same sector. Both, the flux and the torque control are ensured by selecting one of the four non-zero vectors or one of the two null vectors [3] 
$>$ If $\mathrm{Vi}+1$ is selected: The flux amplitude will increase and the torque will increase

$>$ If Vi-1 is selected: The flux amplitude will decrease and the torque will increase.

$>$ If $\mathrm{Vi}+2$ is selected: The flux amplitude will increase and the torque will decrease.

$>$ If Vi-2 is selected: The flux amplitude will decrease and the torque will decrease.

$>$ If V0 or V7 is selected: The vector flux will maintain its value and the torque will decrease if the speed is positive and will increase if speed is negative.

\subsection{Developmentiofifuzzyiswitchingitable}

Today, Fuzzy logic is a technique used in artificial intelligence and with widely used in various areas including: control, automation, robotics ... etc. Indeed this is a new method of dealing with problems of adjustment, control and decision-making.

Those Errors of both torque and the flux are directly used, to select the inverter voltage switche's state with no distinction between a very big error or relatively small in the classical direct control of torque, also the switching state selected in case an important error occurs while starting or with different consigns of torque or flux is the same as during the normal operation. as consequence in a transient regime response of the system is slower, however the voltage vector is selected, and by taking into account the magnitude (amplitude) and signs of the errors of torque and flux and not just their signs, then the responses of the system during starting and when changing the flux control or torque can be greatly improved

We propose in this section a study of direct control of torque application on the double star asynchronous machine based on fuzzy logic.The standard fuzzy logic controller is using membership functions to define the input variable or variables as well as the output variable. They can be of different type but the most frequently used is the triangular membership function [4].

Those hysteresis controllers and switching table of conventional DTC are replaced by a fuzzy controller. The fuzzy controller has three variable state. Inputs and a fuzzy control variable as output to produce a constant control of torque and flux. As is shown in Figure 3 the first fuzzy variable, consisting of three fuzzy sets, is a difference between the amplitude of the flux reference and the estimated flux.

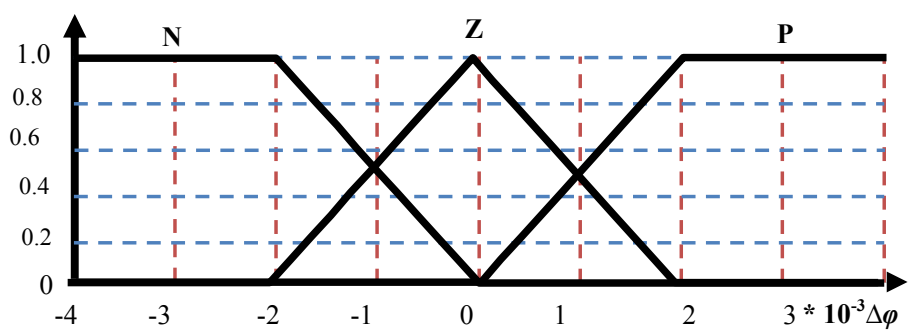

Figure 3. Mumber ship function with three fuzzy subsets for the error flux

The second fuzzy variable is slower consisting of five fuzzy sets. Figure 4 is the difference between the reference torque and estimated torque,

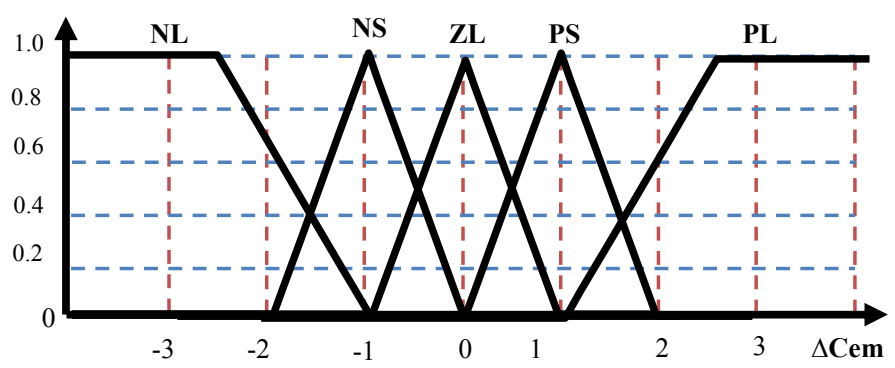

Figure 4. Mumber ship function with five the fuzzy sets

The third fuzzy variable is the angle between the flux stator and there reference axis "angle", the universe of discourse of the third fuzzy variable is divided into twelve fuzzy symmetrical sets. The distribution function of these membership functions is shown in Figure 5. 


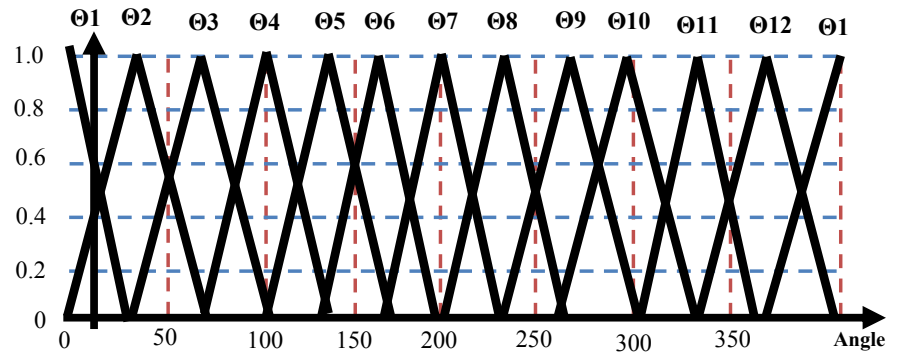

Figure 5. Mumber ship function for the position of the stator flux

The output of fuzzy controller is the proper voltage vector. These voltage vectors are discrete values; singletons represent them as in Figure 6.

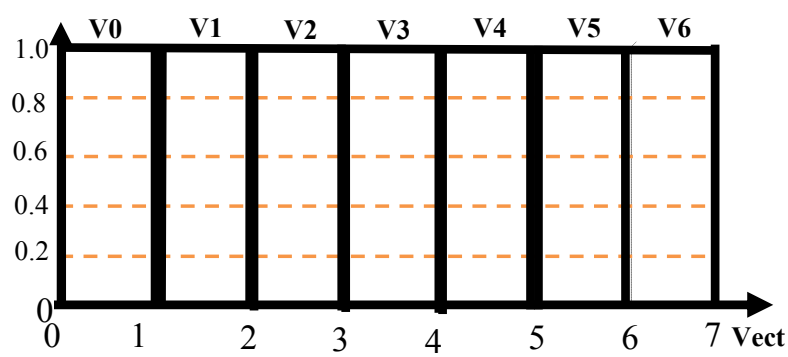

Figure 6. Mumber ship function of the vectors tensions

\subsection{Selection Table for the Voltage Vectors}

Table 1 shows the order of voltage vectors used in the fuzzy direct control method of torque according to voltage vector position and the variation of the torque and flux errors

Table 1. The order of voltage vectors used in the fuzzy direct torque control method

\begin{tabular}{|c|c|c|c|c|c|c|c|c|c|c|c|c|c|c|c|}
\hline & \multicolumn{5}{|c|}{$\Theta 1$} & \multicolumn{5}{|c|}{$\Theta 2$} & \multicolumn{5}{|c|}{$\Theta 3$} \\
\hline$\Delta \Gamma$ & PL & PS & Z & NS & $\mathrm{NL}$ & $\mathrm{PL}$ & PS & $Z$ & NS & NL & PL & PS & $Z$ & NS & $\mathrm{NL}$ \\
\hline $\mathrm{P}$ & V6 & V1 & V0 & V2 & V2 & V6 & V6 & $\mathrm{V0}$ & V1 & V2 & V5 & V6 & V0 & V1 & V1 \\
\hline Z & V6 & V6 & V0 & V0 & V3 & V5 & V5 & V0 & V0 & V2 & V5 & V5 & V0 & V0 & $\mathrm{V} 2$ \\
\hline $\mathrm{N}$ & V5 & V5 & V0 & V4 & V3 & V5 & V4 & V0 & V3 & V3 & V4 & V4 & V0 & V3 & $\mathrm{V} 2$ \\
\hline & \multicolumn{5}{|c|}{$\Theta 4$} & \multicolumn{5}{|c|}{$\Theta 5$} & \multicolumn{5}{|c|}{$\Theta 6$} \\
\hline$\Delta \varphi$ & $\overline{P L}$ & PS & Z & NS & $\mathrm{NL}$ & $\mathrm{PL}$ & PS & $Z$ & NS & $\mathrm{NL}$ & PL & PS & $Z$ & NS & $\mathrm{NL}$ \\
\hline $\mathrm{P}$ & V5 & V4 & $\mathrm{V0}$ & V6 & V1 & V4 & V5 & $\mathrm{V0}$ & V6 & V6 & V4 & V4 & V0 & V5 & V6 \\
\hline Z & V4 & V4 & V0 & V0 & V1 & V4 & V4 & V0 & V0 & V1 & V3 & V3 & V0 & V0 & V5 \\
\hline $\mathrm{N}$ & V4 & V3 & V0 & $\mathrm{V} 2$ & $\mathrm{~V} 2$ & V3 & V3 & $\mathrm{V} 0$ & $\mathrm{~V} 2$ & V1 & V3 & $\mathrm{V} 2$ & V0 & V1 & V1 \\
\hline & \multicolumn{5}{|c|}{$\Theta 7$} & \multicolumn{5}{|c|}{$\Theta 8$} & \multicolumn{5}{|c|}{$\Theta 9$} \\
\hline$\Delta \varphi$ & PL & PS & Z & NS & NL & PL & PS & Z & NS & NL & PL & PS & Z & NS & NL \\
\hline $\mathrm{P}$ & V3 & V4 & V0 & V5 & V5 & V3 & V3 & $\mathrm{V} 0$ & V4 & V5 & V2 & V3 & V0 & V4 & V4 \\
\hline Z & V3 & V3 & V0 & V0 & V6 & V2 & V2 & V0 & V0 & V5 & V2 & $\mathrm{V} 2$ & V0 & V0 & V5 \\
\hline $\mathrm{N}$ & $\mathrm{V} 2$ & $\mathrm{~V} 2$ & V0 & V1 & V6 & $\mathrm{V} 2$ & V1 & V0 & V6 & V6 & V1 & V1 & V0 & V6 & V5 \\
\hline & \multicolumn{5}{|c|}{$\Theta 10$} & \multicolumn{5}{|c|}{$\Theta 11$} & \multicolumn{5}{|c|}{$\Theta 12$} \\
\hline$\Delta \varphi$ & PL & PS & Z & NS & $\mathrm{NL}$ & PL & PS & Z & NS & NL & PL & PS & Z & NS & $\mathrm{NL}$ \\
\hline $\mathrm{P}$ & V2 & V2 & V0 & V3 & V4 & V1 & V2 & $\mathrm{V} 0$ & V3 & V3 & V1 & V1 & $\mathrm{V} 0$ & V2 & V3 \\
\hline Z & V1 & V1 & V0 & V0 & V4 & V1 & V1 & V0 & V0 & V4 & V6 & V6 & V0 & V0 & V3 \\
\hline $\mathrm{N}$ & V1 & V6 & V0 & V5 & V5 & V6 & V6 & V0 & V5 & $\mathrm{V} 4$ & V6 & V5 & V0 & V4 & V4 \\
\hline
\end{tabular}




\section{FIS ALGORITHEM}

The fis used in this study is fuzzy inference system is a system that uses fuzzy set theory to map inputs and outputs.

Our input are: flux errors ef [N Z P], torque error cpl[NS NL ZE PS PL], and the position of the voltage vector $\mathrm{N}\left[\begin{array}{llllllllllll}\theta 1 & \theta 2 & \theta 3 & \theta 4 & \theta 5 & \theta 6 & \theta 7 & \theta 8 & \theta 9 & \theta 10 & \theta 11 & \theta 12\end{array}\right]$ then as output variables we have put six membership singleton S[E1 E2 E3 E4 E5 E6]. The fis type we used in our paper is Mamdani with if -and and-then rule structure, i.e rule Number 01 [if $\mathrm{cf}$ is $\mathrm{P}$ and $\mathrm{cpl}$ is PL and $\mathrm{N}$ is $\mathrm{O} 1$ then Etat is E1].

\section{SPEED ESTIMATOR}

Model Reference Adaptive Systems (MRAS) techniques applied in order to estimate rotor speed. This technique is based on the comparison between the outputs of two estimators. The outputs of two estimators may be (the rotor flux, back emf, or motor reactive power). The estimator that does not involve the quantity to be estimated (The rotor speed $\omega r$ ) is considered as the induction motor voltage model. This model considered to be the reference model (RM). The other model is the current model, derived from the rotor equation, this model considered to be the adjustable model (AM). The error between the estimated quantities by the two models is used to drive a suitable adaptation mechanism, which generates the estimated rotor speed. The Figure 7 shows the architecture of MRAS technique. For speed estimator [5]

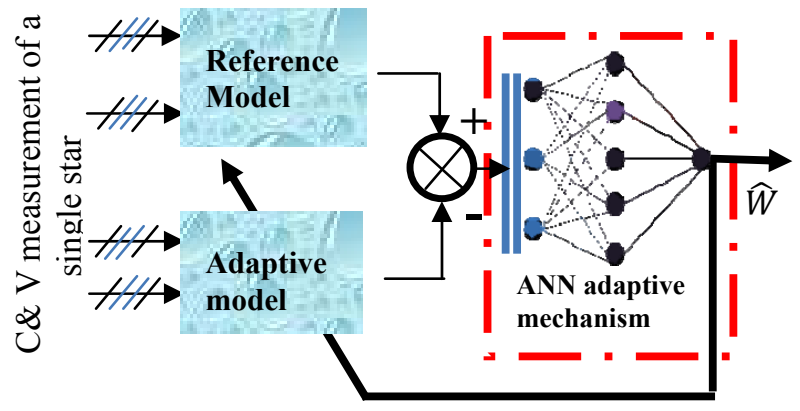

Figure 7. Structure of ANN MRAS Speed Estimator

In our paper the neural network schema used as speed estimator, take the conventional MRAS as a reference and measurement of the speed sensor as target vector for training.

\subsection{Neural Network Speed Estimator in Degraded Mode}

Our proposed structure of the neural network to perform the neural network speed estimator when system stop delivering a full date is a back- propagation controller with seven input nodes, three hidden layer, and one neurons in the output layer, as shown in Figure 8.

In order to simulate the speed estimation in degraded mode we are considering in our study, that one start voltage and current measurements are not available. Moreover, the ANN speed estimator using only those currents and voltages measurements of a single star.

The inputs are currents, voltages, speed (t-1) and the estimated torque. The details of the neural network speed estimator it is showed as in the Figure 9. 


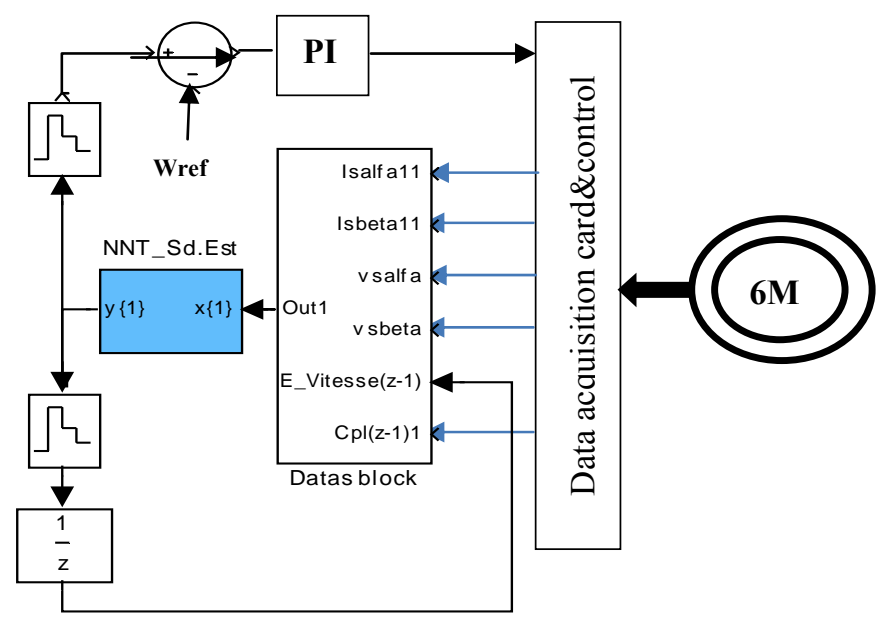

Figure 8. ANN Speed Estimator Block

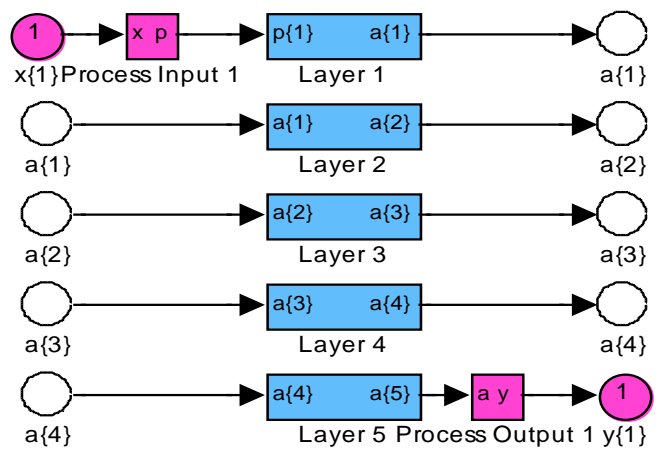

Figure 9. The details of the ANN Speed Estimator

\subsection{ANN Trainiing}

The Figure 10 shows the evolution of the ANN training From the convergence curve we can deduce that is would still be a chance to improve the network parameters by increasing the number of iterations (epochs) to reach enough performance

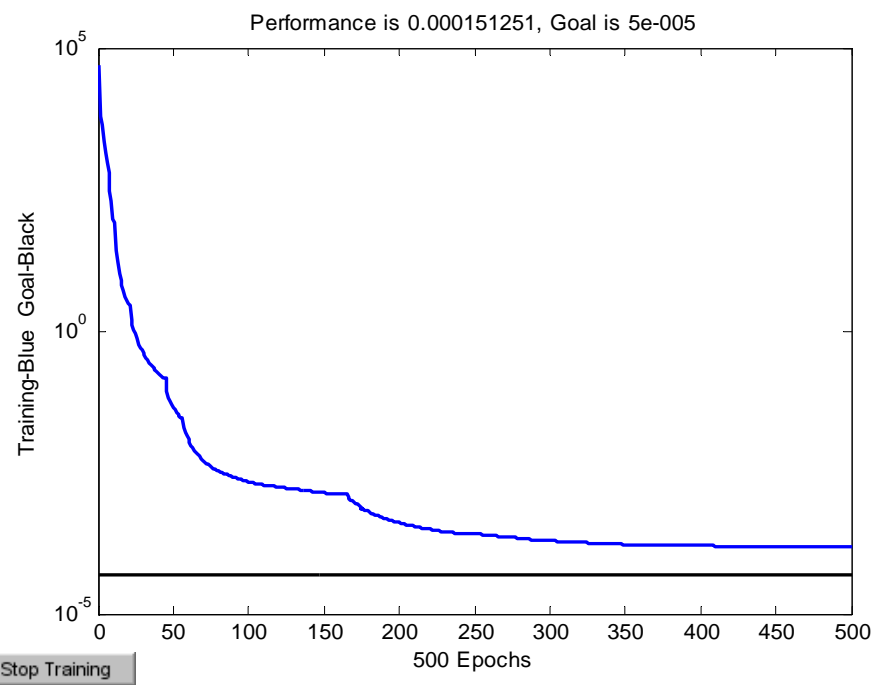

Figure 10. The Evolution of the ANN speed estimator training 


\section{FUZZY DIRECT CONTROL OF TORQUE WITH NEURAL NETWORK SPEED ESTIMATOR}

The modeling and simulation of the control method used to drive the double stars induction machine in this paper contain the state-space formulation in MATLAB/Simulink version 7.10. The proposed method has been successfully implemented in a simulation package use OD4 (range-kutta) as solver. And NEWFF function to develop the ANN speed estimator. The Figure 11 shows the Simulink model of our control proposal.

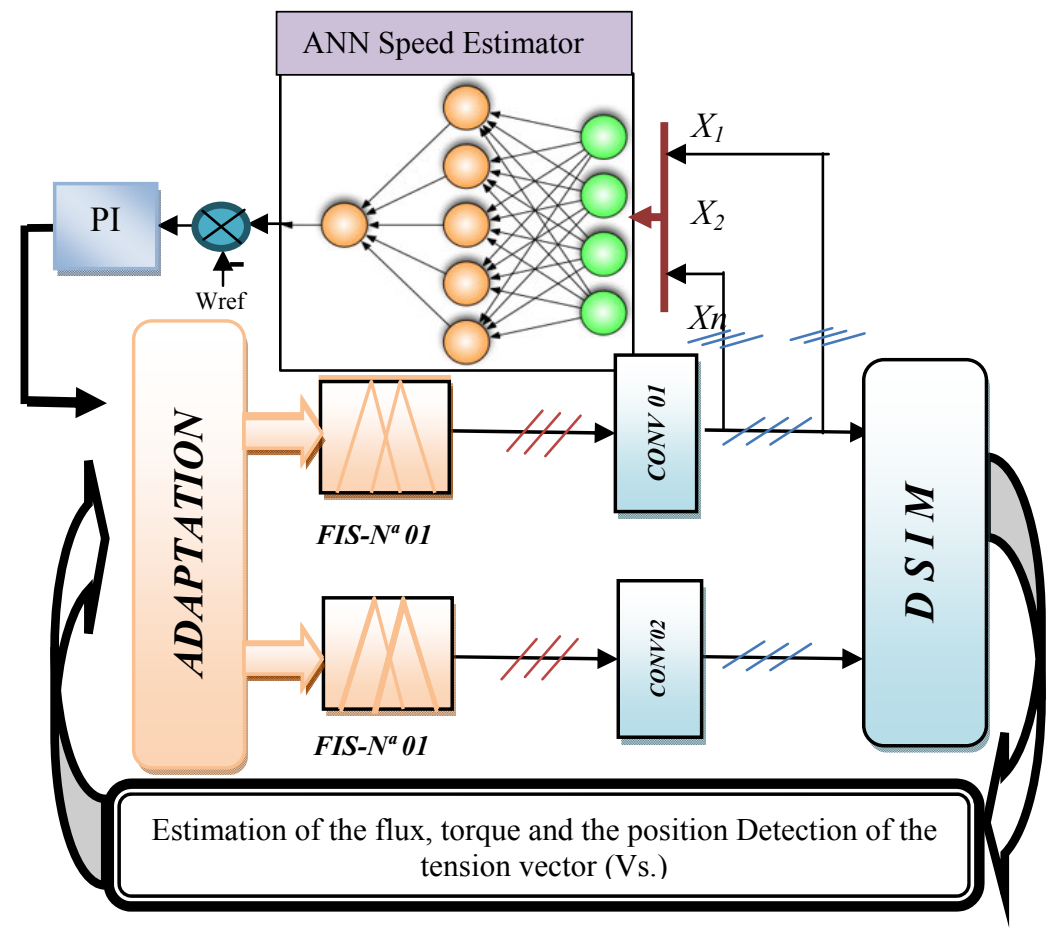

Figure 11. Model of the Fuzzy Direct Control of Torque with ANN Speed Estimator

\subsection{Simulation \& Results Analysis}

After a series of tests with several order combination of layers and nodes, we achieved a very good results by using the configuration mentioned in 11 . The Figure 12 demonstrates the dynamic performance of the PI Controller while starting and in the event of load disturbance. An excess of $0.06 \%$ and a response time of 0.66 secondes characterize the starting time. At $\mathrm{t}=1.5 \mathrm{~s}$ we apply $10 \mathrm{n} . \mathrm{m}$ as load on the motor, the classical controller PI rejects the disturbance with a speed drop of $0.015 \%$ and a rejection time $0.002 \mathrm{~s}$.

The Figure 13 illustrates motor behavior in the event of load disturbance and the enlarged view shows the electromagnetic torque ripples encountered while using the fuzzy direct method of torque control, the torque ripple is reduced by $50 \%$ compared with the classical method of direct control of torque.

Figure 14 shows the form of the electromagnetic flux when using the direct method of torque control, also the high quality of the uncoupling between flux and torque, it also shown the flux reaching the reference value with a ripple rate of $0.41 \%$. In the same figure, we can see the evolution of the flux and the uniformity between both flux components, which approve that the flux has a constant distribution in side the machine winding. 


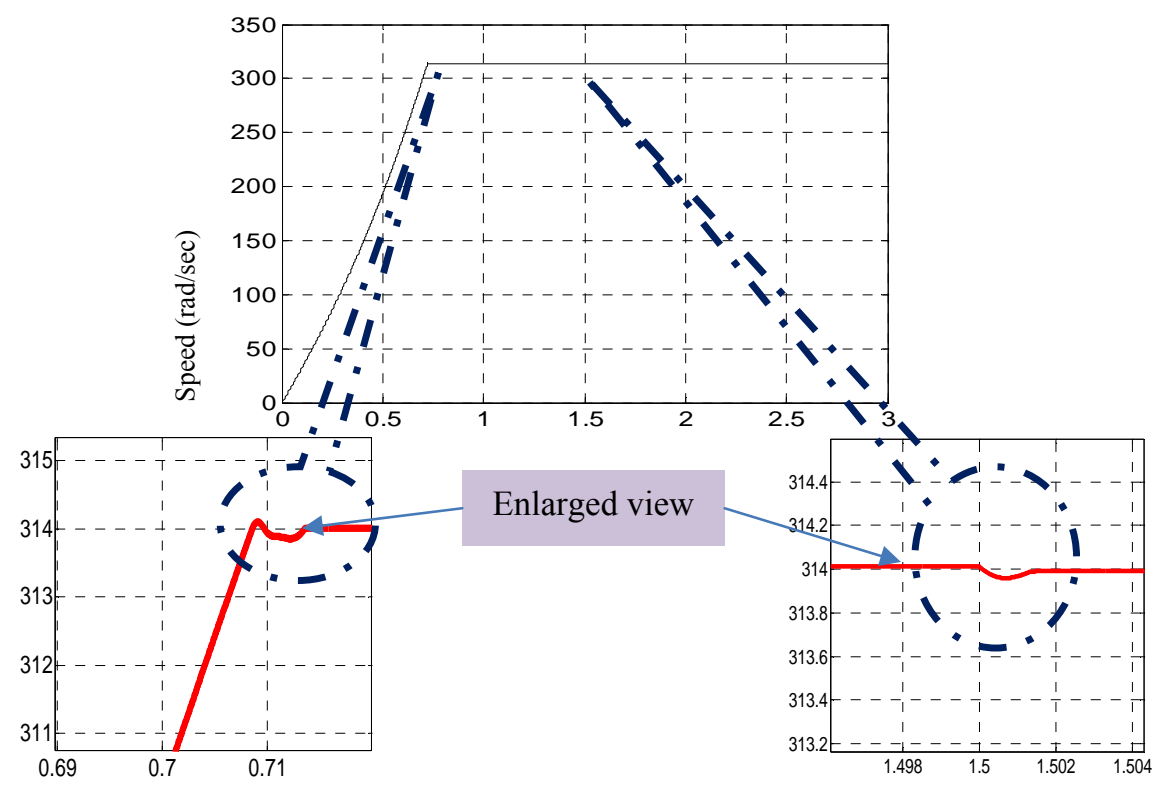

Figure 12. PI Dynamic Performance of FDTC
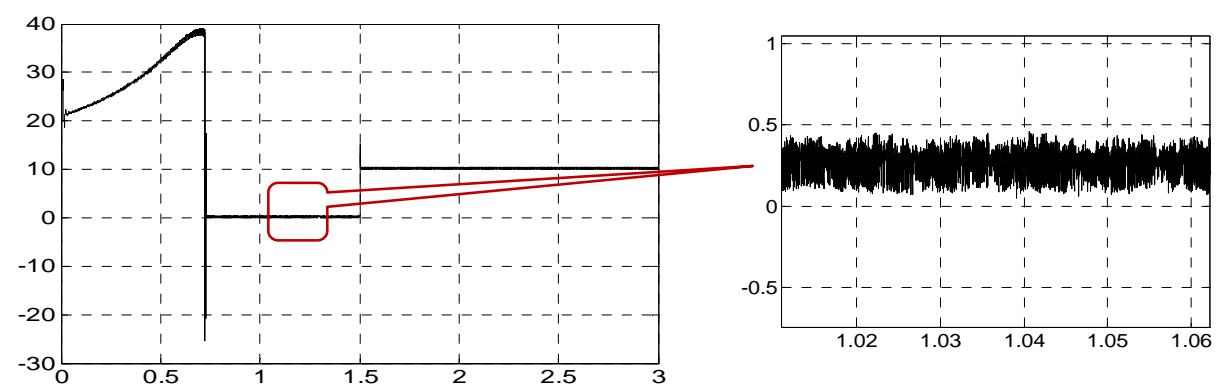

$\sec$

Figure 13. Enlarged view of the torque ripple
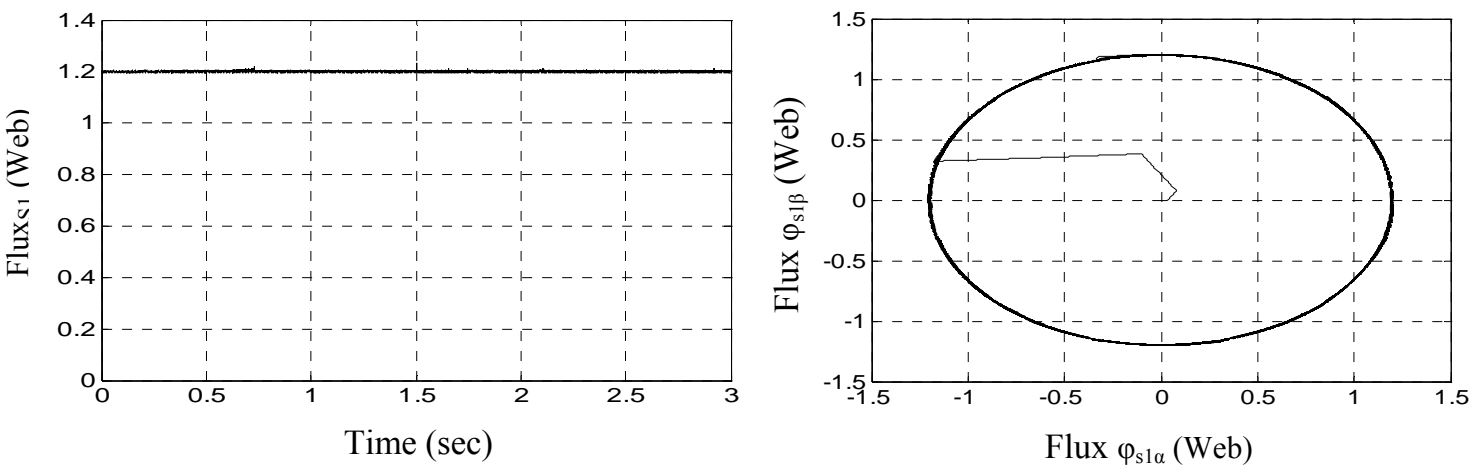

Figure 14. Electromagnetic flux behavior

The Figure 15 shows the performance of the ANN speed estimator where E present the ANN speed estimation and $\mathrm{M}$ present the measurement speed. We can see the high capacity of the estimation provided by the ANN Estimator. The Figure 16 shows the speed estimation error between the measurement speed and the estimation speed when use the ANN Estimator. 


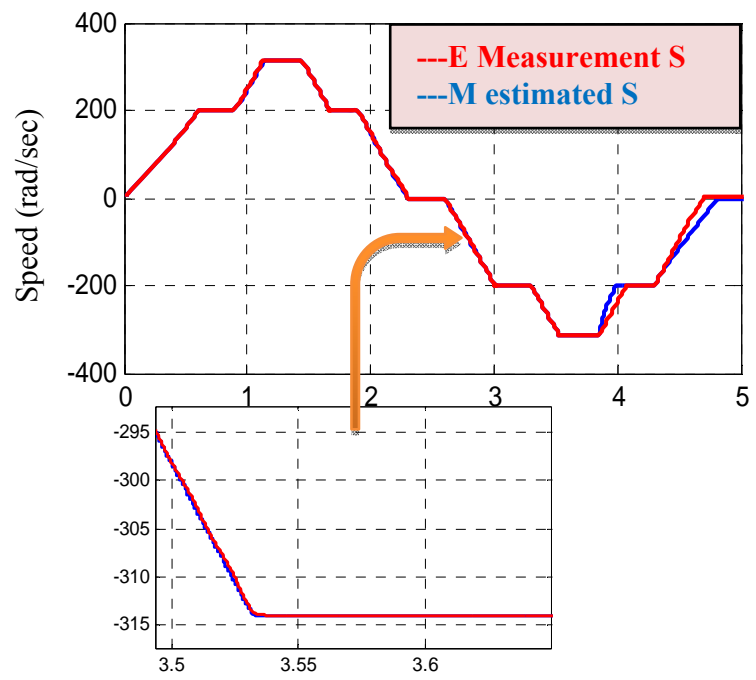

Figure 15. Measurement and Estimated Speed

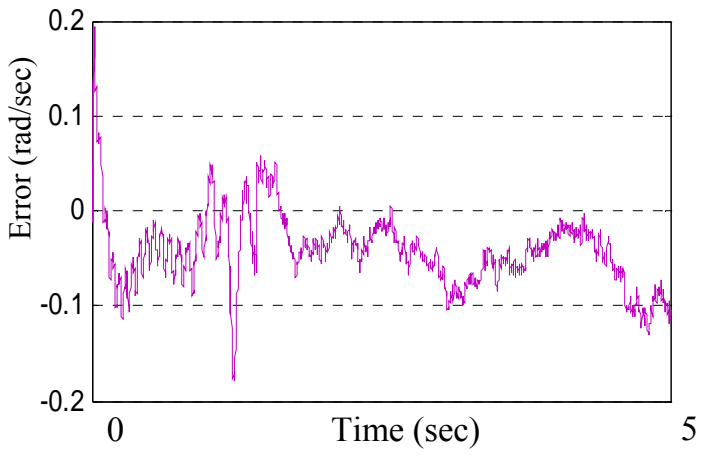

Figure 16. Error between the Measurement \& estimated speed

Figure 17 shows the harmonic Order of the stator current, it is clear that the fuzzy direct control of torque control method improved the total harmonic distortion (THD) when we compare with the classic direct control of torque.
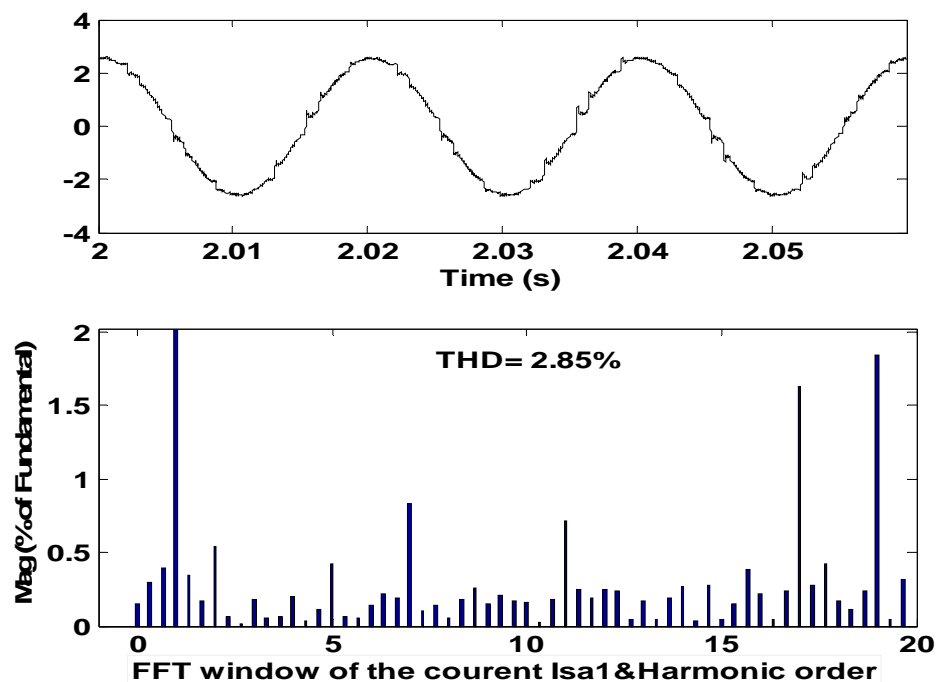

Figure 17. Harmonic Order of the stator current

\section{CONCLUSION}

The same control law was proven to exist when using a combination of the artificial neural network as estimator in a degraded mode and the fuzzy logic as converter switchs controller. The intention of this paper is to substantiate that logic and to provide the reader with the results of the exercise and the supportive evidence.

With the ANN speed estimator method operating in a degraded mode, the simulation of the double star induction motor using direct fuzzy control of torque demonstrated a superior performance of fuzzy direct torque control when compared with the conventional direct control of torque. We have established by demonstration that with the introduction of the new type of control and ANN estimator there are performance advantages as such which within this paper it has been established that the ANN has become an optimal 
solution for those Sensor-less control techniques when operating in both normal and degraded modes providing the end user with:

1. A significant minimization of the electromagnetic torque ripple.

2. High quality of ANN speed estimation;

3. Achieving faster response times on the torque;

4. A significant reduction of the load disturbance rejection time with a low speed dropout rate;

5. Total elimination of the excess and a considerable decrease in the starting time.

\section{REFERENCES}

[1] R. Abdessemed, "Modélisation et simulation des machines électriques”, Ellipses Édition Marketing S.A, 2011.

[2] J. poul Louis"Commande classique et avancées des actionneurs synchrones", EGEM, 2010

[3] C. Canulas de wit carlos, "Modélisation contrôle vectoriel et DTC", commande des moteurs asynchrones 1 MERMES science Europe. 05, 2000

[4] A. Tomova, M. Antchev, M. Petkova, H. Antchev, "Fuzzy Logic Hysteresis Control of A Single-Phase on-Grid Inverter: Computer Investigation", (IJPEDS), Vol. 3, No. 2, June 2013, pp. 179 184 ISSN: 2088-8694

[5] Z.M. El-Barbary, M. K. Metwally, H. Z. Azazi, "A Cost Effective sensorless vector control of 4-Switch 3-Phase Inverter Fed IM using MRAS”, (IJPEDS), Vol.1, No.2, December 2011, pp. 113 120 ISSN: 2088- 8694

[6] H. Demuth COPYRIGHT $1992-2000$ by the MathWorks, Inc. Neural Network Toolx.

[7] I. Takahashi, T.Noguchi "new quickresponse and high-efficiency control" strategy of induction motor", IEEE Trans. On IA, Vol.22, $\mathrm{N}^{\circ} .5$, PP.820-827.

[8] J. Paul Louis, "Commandes d'actionneurs électriques synchrones et spéciaux”, EGEM, 2012

[9] J. sury, I. sic youni, K. sang lee \& S. chan hong, "Direct Torque Control of Induction Motors Using Fuzzy Variables witching Sector", Industrial Electronics [2001. Proceedings. ISIE 2001. IEEE] International Symposium on, Vol. 2.

[10] E. Monmasson, "Commande rapprochée de convertisseur statique 01", EGEM, 2009.

[11] G. Grellet, G. Clerc, " Principe /modèle / commande”, 1D.I.S.T.N.B Actionneurs électriques.

[12] M. Bellier, A.Galichon, “Électricité industriel : Machines Electriques.”

[13] K. Marouani, A.Kheloui, "Implantation Numérique de la Commande Directe du Couple d'une Machine Asynchrone", ICEL 2000 U.S.T.O ALGERIE.

[14] L. Loron, "Commande du système électrique”, Lavoisier, 2003, Paris.

[15] L. Dor londan, "Commande des systems", Lavoisier, 2002, Paris.

[16] M. Depenbrock, "Direct self - control (DSC) of inverter- fed induction machine", IEEE Trans. Power Elec.

[17] R.mf, Haque MDF, T. Lixin, "all. Problems associated with the direct torque control of an interior Permanent magnet synchronous motor drive and their remedies”, IEEE Trans. on Industrial Electronics, 2004, 51(4).799-809. 